\title{
Substance Screening
}

National Cancer Institute

\section{Source}

National Cancer Institute. Substance Screening. NCI Thesaurus. Code C142721.

Random or targeted evaluation of material using biochemical tests or assays

constructed to identify a particular biological aspect or action. 